\title{
CAPítulO 5
}

\section{A ROTULAGEM AMBIENTAL TIPO I NO PROCESSO DE COMPRAS PÚBLICAS SUSTENTÁVEIS DO BRASIL}

Antônio José Juliani

Os padrões de produção e de consumo vigentes na sociedade global derivam do desenvolvimento industrial e do desenvolvimento tecnológico que são caracterizados pela oferta de bens e de serviços em larga escala. Os hábitos das sociedades ocidentais modernas contribuem para o excesso de consumo de bens desnecessários e muitas vezes supérfluos e para a produção de resíduos (Cortez e Ortigoza, 2007). O nível de exploração dos recursos naturais para a obtenção de matéria-prima se encontra em níveis superiores à capacidade de suporte dos ecossistemas que é comprovado pelo fenômeno do aquecimento global, pela poluição dos mares, dos rios e dos mananciais e pela extinção de espécies da fauna e da flora (Veiga, 2005).

De acordo com Stern (2007), os impactos potenciais e irreversíveis do aquecimento global nos ecossistemas, nas sociedades e nas economias, começam a ser conhecidos e mensurados. Interromper a tendência do aumento das temperaturas globais requer eficiente transição na direção da economia de baixo carbono cujo atraso pode tornar a questão climática um problema de difícil solução para a humanidade. A partir da década de 1990 observou-se mudança no enfoque das discussões relacionadas com os problemas ambientais, na medida em que os questionamentos sobre os impactos causados pelos 
padrões de consumo ganharam espaço, em relação às abordagens que consideravam apenas problemas relacionados com a atividade produtiva (Portilho e Russo, 2008).

Nesse contexto, surgiram expressões como: consumo sustentável, consumo consciente ou consumo responsável, para denominar o uso de bens e de serviços que atendem às necessidades básicas, à melhoria da qualidade de vida e à produção de menores impactos em relação ao meio ambiente. A compreensão de consumo sustentável parece materializar o próprio conceito de desenvolvimento sustentável contido no Relatório Brundtland (PNUMA, 2001). Dessa forma, torna-se necessário que a satisfação das necessidades da sociedade moderna esteja em consonância com o uso racional de recursos naturais para que possa contribuir para a mudança dos padrões de produção e de consumo vigentes para padrões mais responsáveis.

No cenário internacional, a Agenda 2030, adotada pelas Nações Unidas em 2015, propõe a adoção de 17 Objetivos de Desenvolvimento Sustentável (ODS), que se subdividem em 169 metas correspondentes. Destaca-se o ODS 12, que propõe assegurar a produção e o consumo sustentável por meio da promoção de compras públicas sustentáveis (meta 12.7) e de acordo com as políticas e prioridades nacionais. As Nações Unidas reconhecem que as compras públicas são importantes no processo de inovação e de transição para uma economia verde, uma vez que a necessidade de preencher critérios de sustentabilidade incorporados aos editais das licitações públicas impulsiona o mercado rumo à adoção da inovação dirigida para a sustentabilidade.

Para as Nações Unidas, a compra pública tem o potencial de criar sinergias entre inovação, desenvolvimento econômico e proteção ambiental. E com ela, os governos, no papel de consumidores líderes da sustentabilidade, incentivam a mudança nos padrões de produção e de consumo da sociedade por meio da exigência de produtos e de serviços responsáveis em relação ao meio ambiente. Assim, se inicialmente, a figura do consumidor foi associada ao indivíduo, a ampliação do tema resultou na percepção de que as instituições públicas e privadas, também são consumidoras expressivas de bens e de serviços e podem apresentar níveis de consumo mais significativos do que os das pessoas físicas (Portilho e Russo, 2008).

No Brasil, de acordo com o Ministério do Planejamento, Orçamento e Gestão (MPOG, 2010), as compras governamentais movimentam cerca de 10\% a 15\% do Produto Interno Bruto do País. Esses valores mostram a importância dos atores governamentais como consumidores de produtos e de serviços e tem 
estimulado países a elaborar guias e planos de ação com o objetivo de implementar mecanismos de gestão ambiental nos órgãos públicos.

Nesse contexto, surgem as compras públicas sustentáveis (CPS) ou licitações sustentáveis que são apontadas como um relevante instrumento de gestão ambiental para os órgãos governamentais. As CPS, com os órgãos públicos na condição de consumidores, têm a capacidade de estimular o mercado verde e a economia circular, levando as empresas a adotarem práticas sustentáveis nos seus processos produtivos, como o design sustentável, a diminuição de resíduos, o reuso de materiais, a reciclagem e o uso de rótulos ambientais.

No Brasil, foram desenvolvidas várias ações no sentido de constituir uma Política Pública para CPS. Exemplos são: a Agenda Ambiental na Administração Pública A3P, na qual foi inserido um eixo temático específico sobre licitações sustentáveis e a elaboração de Guias de Compras Públicas Sustentáveis pelo Ministério do Planejamento, Orçamento e Gestão (MPOG) e pelo Ministério do Meio Ambiente (MMA). Em 2007, foi elaborado o Plano de Ação para a Produção e o Consumo Sustentável (PPCS), alinhado às ações do Processo de Marrakesh, para fomentar a adoção de padrões de produção e de consumo sustentáveis no Brasil.

Em 2010, foi elaborada a Instrução Normativa (IN) $n^{\circ} 1$ (MP), que dispunha sobre os critérios de sustentabilidade ambiental na aquisição de bens, contratações de serviços ou obras pela administração pública direta, autárquica e fundacional. Em 2012, foi publicado o Decreto ${ }^{0}$ 7.746, com o objetivo de regulamentar o art. $3^{\circ}$ da Lei $n^{\circ} 8.666$, de 21 de junho de 1993, para estabelecer critérios, práticas e diretrizes para a promoção do desenvolvimento nacional sustentável, nas contratações realizadas pela administração pública federal, e instituir a Comissão Interministerial de Sustentabilidade na Administração Pública (CISAP).

Além dessas ações, o governo federal, por meio do MPOG, desenvolveu um sistema de compras informatizado com catálogo de produtos sustentáveis que pode ser utilizado pelos diversos órgãos como referência para a inclusão de critérios de sustentabilidade nas especificações dos bens e serviços dos editais de licitação.

Apesar da relevância e das repercussões políticas, econômicas e sociais positivas dessas ações, observa-se, ainda, a necessidade de aprimoramento do processo de compras públicas sustentáveis no Brasil para que possa efetivamente ser um instrumento indutor da mudança de padrões de produção e de consumo no País. 
Existem duas prioridades que devem ser atendidas para o fortalecimento da variável de sustentabilidade no ciclo de vida do processo de CPS nacional. Uma delas é a criação de critérios de sustentabilidade para a aquisição de bens e de contratações de serviços e a outra é o aperfeiçoamento do mecanismo de verificação desses critérios pelos órgãos públicos compradores ou contratantes.

Atualmente, a maioria dos critérios classificados como critérios de sustentabilidade no processo das compras públicas sustentáveis, relacionam-se com as especificações técnicas do produto, e a verificação pelos órgãos públicos é feita, principalmente, por meio de autodeclarações dos fabricantes/fornecedores que asseguram que seus produtos e serviços são sustentáveis e preenchem os critérios de sustentabilidade exigidos.

\section{A DIFÍCIL ESCOLHA DA SUSTENTABILIDADE NO PROCESSO DE COMPRAS PÚBLICAS SUSTENTÁVEIS}

A escolha do produto ou serviço mais sustentável que outros similares no mercado é um dos passos mais importantes para a realização de uma licitação sustentável, em função da proliferação de definições de produtos sustentáveis existentes. Alguns produtos são considerados sustentáveis quando geram menos resíduos nos seus processos produtivos, quando são recicláveis ou mais duráveis, outros quando não são constituídos por substâncias que são prejudiciais ou tóxicas à saúde humana ou quando seu processo produtivo é menos intensivo em energia, em água ou emite menos gases de efeito estufa.

Para decidir qual produto é preferível em termos ambientais, os pesquisadores e os especialistas recomendam a comparação dos impactos ambientais dos produtos por meio da avaliação de seus ciclos de vida. Na verdade, produto sustentável é aquele que apresenta o melhor desempenho ambiental ao longo de seu ciclo de vida, com função qualidade e nível de satisfação igual ou melhor, se comparado com um produto-padrão (BIDERMAN et al., 2008).

Na prática, nem sempre é fácil encontrar critérios de sustentabilidade adequados para a aquisição de um produto, ou de um serviço, geralmente, eles não estão relacionados com o desempenho ambiental desses produtos ou serviços. Além disso, o próprio servidor que trabalha com compras públicas sustentáveis não possui capacitação efetiva no tema, e um dos desafios mais comuns para a implementação da licitação de produtos sustentáveis é a falta de informação e de experiência do consumidor (órgãos públicos) para fazer a comparação das características de um produto específico. 
Em alguns casos, o consumidor é sobrecarregado com informações sobre a sustentabilidade dos produtos pelos próprios fabricantes, fato que cria a necessidade de verificação da veracidade dessas informações, por parte do órgão comprador.

Existem instrumentos práticos que ajudam a ultrapassar esses obstáculos e que são utilizados em países que possuem política efetiva de compras públicas sustentáveis, como os Estados Unidos, a Inglaterra, o Canadá, a Coréia do Sul, o Japão e a Alemanha, dentre outros. Tais instrumentos baseiam-se na metodologia de Avaliação de Ciclo de Vida (ACV) que é um conceito holístico para avaliar o desempenho ambiental de um produto ou de um serviço. A ACV leva em conta o impacto ambiental do produto em seu ciclo de vida, ou seja, em todos os seus estágios, desde a extração da matéria-prima até a disposição final do produto com o propósito de minimizar os impactos negativos no meio ambiente.

Deve-se ressaltar que esses instrumentos levam em consideração os princípios da Economia Circular, que surgiu a partir de modelo da ecologia industrial baseado na ideia de ciclos fechados que eram utilizados pelas políticas ambientais da Alemanha e da Suécia no início da década de 1970 (YUAN et al., 2006). A Economia Circular é uma alternativa ao sistema de produção linear com o objetivo de transformar bens de consumo, que seriam descartados como rejeitos, em recursos para outros setores da economia, fechando ciclos no ecossistema industrial e minimizando a produção de resíduos. O processo inovador é procurar substituir a produção linear com recursos que podem ser reusados, reparados, remanufaturados (STAHEL, 2016).

\section{ALGUMAS CONSIDERAÇ̃̃ES SOBRE A AVALIAÇÃO DO CICLO DE VIDA (ACV)}

A definição de Avaliação de Ciclo de Vida (ACV), segundo a ISO/TC 207 é: "a compilação e a avaliação das entradas, das saídas e dos impactos ambientais potenciais de um sistema de produto ao longo do seu ciclo de vida". A ACV é uma ferramenta desenvolvida para auxiliar a busca contínua de desempenho ambiental. Ao contrário de outras técnicas comumente utilizadas em avaliações ambientais, a ACV tem uma abordagem relativa e apresenta algumas características específicas. É considerada como um ponto de partida para os programas de rotulagem ambiental (SETAC, 2002).

De acordo com a ISO 14040, a ACV aborda todos os potenciais aspectos e impactos ambientais ao longo de todo o ciclo de vida do produto, compreendendo as atividades de extração e aquisição da matéria-prima, bem como a produção, utilização, reciclagem e por último a disposição final. As normas desenvolvidas 
pela Organização Internacional de Normalização (ISO) sobre ACV, harmonizam os procedimentos adotados nas iniciativas tomadas em vários países do mundo por institutos de pesquisa e empresas interessados em demonstrar o desempenho ambiental e a aceitação dos produtos no mercado.

De um lado, o fato de considerar as diferentes etapas do ciclo de vida do produto, desde a obtenção da matéria-prima até a disposição final do produto, faz da ACV um instrumento eficiente de melhoria ambiental, pois também considera questões como a transferência de impactos ambientais de uma etapa do ciclo de vida do produto para outra, ou de um meio para outro, sem que haja um ganho ambiental líquido (IPEA, 2011).

Por outro lado, ao se implementar a abordagem do ciclo de vida no estabelecimento dos critérios dos rótulos ambientais, o uso da ACV também pode apresentar algumas dificuldades e limitações como: a grande extensão dos estudos, os altos custos envolvidos, a dificuldade de obtenção de dados que nem sempre estão disponíveis, e o longo prazo para o alcance dos resultados. A solução para o problema encontra-se no princípio da consideração de aspectos do ciclo de vida.

É recomendação da ISO na norma 14024 que determinados critérios ambientais levem em consideração o ciclo de vida do produto, sem que haja necessidade de se conduzir uma avaliação completa desse ciclo. Isto é feito mediante uma apreciação de aspectos do ciclo de vida do produto, com a identificação das fases críticas em relação aos impactos potenciais que serão objeto de estudos mais aprofundados.

Tal abordagem deve incluir uma avaliação significativa do conjunto dos impactos para embasar a seleção daqueles que serão utilizados na definição dos critérios. O envolvimento das partes interessadas no processo de definição de requisitos é importante para assegurar a sua legitimidade e a sua adequação. Uma das formas empregadas para esse fim é a constituição de comitês com representantes dos setores interessados para a condução dos trabalhos.

A condução de uma $\mathrm{ACV}$ requer investimento considerável de tempo e de recursos, mas apesar disso, tanto organizações privadas quanto órgãos públicos usam essa ferramenta como apoio para tomada de decisões. Pode ser utilizada como, por exemplo, no desenvolvimento de políticas públicas de rotulagem ambiental, que são instrumentos de mercado importantes no processo das compras públicas sustentáveis do País. 


\section{ASPECTOS DA ROTULAGEM AMBIENTAL}

$\mathrm{O}$ aumento da consciência da sociedade em relação às questões ambientais tem provocado efeitos importantes nos mercados consumidores de produtos e de serviços. Esses efeitos têm se apresentado como uma crescente demanda por informação sobre os aspectos ambientais envolvidos nos processos produtivos, fato que influencia de forma significativa, a decisão de compra dos consumidores (MMA, 2002).

Esse cenário deu origem ao surgimento de centenas de iniciativas de veiculação de informação sobre a sustentabilidade socioambiental dos processos produtivos e do uso dos mais variados produtos e serviços. Nem sempre essas informações são críveis.

Muitas dessas iniciativas podem ser classificadas como rotulagem ambiental. Não existe uma definição consensual que descreve seus conceitos básicos nem uma disciplina única que a explique integralmente. É matéria interdisciplinar e pode ser entendida como um rótulo que identifica a preferência ambiental global de um produto ou de um serviço, dentro de uma categoria específica de produtos/serviços, com base em considerações sobre o ciclo de vida.

De acordo com Grote (2002), rotulagem ambiental é a prática de informar os consumidores sobre um produto que se caracteriza por um melhor desempenho ambiental em comparação com produtos similares. Consiste, basicamente, na atribuição de um selo ou rótulo a um produto ou serviço para informar sobre seus aspectos ambientais econômicos e sociais.

Trata-se de um instrumento econômico e um instrumento de comunicação, visto que busca difundir informações que alterem positivamente padrões de produção e de consumo, aumentando a consciência dos consumidores e dos produtores para a necessidade de usar os recursos naturais de forma mais responsável. Procura, com base na informação acurada e verificável acerca dos aspectos ambientais de produtos e de serviços, encorajar a demanda por aqueles produtos que causem menores impactos no meio ambiente.

Outras expressões também são utilizadas para designar rotulagem ambiental como selo verde ou ecológico, declaração ambiental, rótulo ecológico, ecorrótulo, ecosselo e etiqueta ecológica (IPEA, 2011).

Muitas vezes, rotulagem e certificação também são usadas como sinônimos; contudo, a rotulagem ambiental (ecolabelling) geralmente relaciona-se às características do produto e destina-se aos consumidores finais, enquanto que a certificação ambiental (ecocertification) está relacionada com os métodos e 
processos de produção, sendo direcionada, principalmente, para as indústrias utilizadoras de recursos, objetivando atestar um ou mais atributos do processo de produção (IPEA, 2011).

Em virtude da proliferação de muitos rótulos e de selos ambientais nos mercados globais e da necessidade de se estabelecer padrões e regras para o uso adequado, a ISO desenvolveu normas para a rotulagem ambiental e classificou os diversos tipos de rotulagem em três tipos principais: Tipo I (ISO 14024), Tipo II (ISO 14021) e Tipo III (ISO 14025) (BRASIL, 2002).

A rotulagem ambiental tipo I é conferida por programas de terceira parte (não é o fabricante, nem o fornecedor), está fundamentada em múltiplos critérios, é voluntária e considera aspectos do ciclo de vida do produto. Também é conhecida como selo verde. A rotulagem ambiental tipo II corresponde às autodeclarações ambientais informativas que são elaboradas pelos próprios fabricantes e/ou fornecedores. Já a rotulagem ambiental Tipo III também é conferida por programas voluntários de terceira parte e fornecem informações amplas e quantificadas e baseadas em uma ACV completa. Está ainda em desenvolvimento, principalmente, no setor acadêmico (MMA, 2002).

Existem outros tipos de rótulos ambientais bastante específicos, mas que não foram regulamentados pela ISO como, por exemplo, a certificação de agricultura orgânica, na qual se atesta que determinados produtos agrícolas, como alimentos ou produtos têxteis, por exemplo, são provenientes de produções que não utilizam substâncias químicas. Outro exemplo são os selos neutros, que informam, resumidamente, características ambientais sobre um produto para orientar o consumidor. É o caso do selo Procel, de conservação de energia, que permite ao consumidor escolher um produto de menor consumo energético comparando-o aos demais da mesma categoria.

Estes programas alternativos se concentram geralmente em um único setor ou abarcam apenas um problema ambiental e não consideram o ciclo de vida do produto em suas aplicações. São geralmente, monocriteriais.

Em um típico programa de rotulagem ambiental tipo I, as categorias de produtos e os critérios são determinados por uma organização independente, com a ajuda de um grupo de assessoria técnica complementar. A partir do momento em que uma categoria é escolhida, alguma forma de ACV é conduzida. As empresas que optarem por submeter seus produtos/serviços ao programa de rotulagem ambiental tipo I, para obter o rótulo (logo) correspondente, preenchem um contrato e apresentam os seus produtos para testes de conformidade e de verificação que são feitos por uma organização de terceira parte (auditoria). 
Se os produtos forem aprovados e preencherem os critérios definidos, as empresas pagam taxas de licenciamento para o uso do logo do programa de rotulagem por um determinado período, com a necessidade de nova avaliação (auditoria) para renovação. $\mathrm{O}$ uso do rótulo ambiental se restringe ao produto aprovado e a planta industrial onde ele é fabricado e será monitorado pela agência de gestão.

A rotulagem ambiental tipo I é considerada a mais adequada para compor o sistema de verificação da sustentabilidade no processo de compras públicas sustentáveis garantindo a imparcialidade e a credibilidade necessárias.

É voluntária, considera aspectos do ciclo de vida do produto, ou seja, não leva em consideração apenas especificações técnicas do produto, mas avalia todo o seu processo produtivo, além de ser conferida por um organismo de terceira parte que não representa o produtor, o fornecedor, ou qualquer outra parte interessada nos aspectos comerciais.

\section{A ROTULAGEM AMBIENTAL TIPO I E A VERIFICAÇÃOO DA SUSTENTABILIDADE NAS CONTRATAÇ̃̃ES PÚBLICAS SUSTENTÁVEIS}

As contratações públicas sustentáveis constituem instrumentos relevantes de contribuição para a reorganização da economia com novos paradigmas. No Brasil, inserem-se em um contexto de agendas nacionais que orientam as ações e as políticas para o desenvolvimento sustentável. Sob tal perspectiva, as contratações públicas representam a adequação da contratação ao que se chama consumo sustentável.

De acordo com Bildermam et al. (2008), a licitação sustentável é uma solução para integrar as considerações ambientais e sociais em todos os estágios do processo de compra e contratação de agentes públicos (governos) com o objetivo de reduzir impactos à saúde humana, ao meio ambiente e aos direitos humanos. O objetivo dessas licitações é, por força legal, assegurar a livre concorrência e obter o melhor produto/serviço com a proposta mais vantajosa.

A proposta mais vantajosa para a administração pública deve levar em conta não apenas o menor preço, mas o custo como um todo, considerando a preservação do meio ambiente e o bem-estar social das populações. De acordo com Costa (2011), a proposta mais vantajosa não é, nem deveria ser interpretada como sinônimo de menor preço. Além disso, observa que mesmo nos casos em que um produto sustentável tem maior preço, muitas vezes o custo de manutenção e de descarte correspondentes são menores. 
A introdução da variável sustentabilidade com a consideração das dimensões econômica, social e ambiental, no processo de compras públicas, aumenta a complexidade do mesmo, uma vez que, além da preocupação com os gastos financeiros, deve-se considerar os impactos que as contratações podem causar ao meio ambiente e à sociedade.

Deve-se levar em conta, os recursos públicos de forma ampla e responsável. É grande a responsabilidade do gestor público para manter, além da livre concorrência, o menor custo financeiro, social e ambiental, de modo a assegurar que a proposta mais vantajosa seja realmente mais vantajosa para o conjunto da sociedade, que é a detentora do bem público.

Mesmo diante da grande contribuição decorrente da alteração promovida pela Lei $n^{0}$ 12.349/2010, no âmbito do governo federal brasileiro, o status de primeiro marco regulatório para inserção de critérios de sustentabilidade nas contratações públicas é atribuído à Instrução Normativa (IN) n ${ }^{\circ} 1$, de 2010 . Por meio da expedição desta IN, o Ministério do Planejamento, Orçamento e Gestão (MPOG) estabeleceu instruções a serem observadas na aquisição de bens e na contratação de serviços ou obras pelos órgãos da administração pública federal direta, autárquica e fundacional.

Com a publicação da IN n $n^{0}$, as compras públicas sustentáveis ampliaram o conceito de contratação mais vantajosa nas licitações públicas, pois passaram a considerar a aquisição de produtos menos danosos ao meio ambiente e não apenas aqueles de menor preço (PEA, 2011).

Também foi recomendado pela mesma Norma a inclusão de critérios de sustentabilidade nas contratações públicas sustentáveis, porém ainda não se tem um sistema crível, efetivo e dinâmico de elaboração de critérios e da verificação da sustentabilidade exigida. Sabe-se que em muitos países desenvolvidos como Coreia do Sul, Japão, Estados Unidos e Alemanha, essa verificação é feita por meio do uso da rotulagem ambiental tipo I.

Sabe-se, também, que os programas de rotulagem ambiental tipo I possuem critérios de sustentabilidade criados para variadas categorias de produtos/serviços que levam em consideração aspectos do ciclo de vida desses produtos/serviços. Não é feita uma ACV completa do ciclo de vida, por se tratar de processo oneroso, que demanda longo prazo para execução e cuja metodologia ainda está sendo aperfeiçoada em nível global.

Seguindo as instruções da Norma ISO 14024, os programas de rotulagem ambiental tipo I fazem a ACV baseados em aspectos do ciclo de vida de produtos/serviços, ou seja, não avaliam o ciclo de vida na totalidade, mas identificam 
os pontos críticos desse ciclo, nos quais a probabilidade de ocorrerem impactos ao meio ambiente e à saúde humana são significativos. Os critérios são criados, então, para que sejam avaliados esses pontos críticos por meio da auditoria.

A relevância desses critérios de sustentabilidade criados poderá ser considerada pelos gestores públicos responsáveis pelas compras públicas sustentáveis e poderão ser transcritos para os termos de referência dessas licitações. Dessa forma, incluídos no processo público, poderão ser avaliados por uma auditoria independente, do programa de rotulagem ambiental tipo I. Fato que traz maior parcialidade e credibilidade ao processo público.

Em países onde ainda essa prática não é utilizada e com o objetivo de promover o uso da rotulagem ambiental tipo I nas compras públicas sustentáveis, não se exige que o produto licitado tenha o rótulo ambiental tipo I. A obtenção do rótulo, geralmente, demanda o preenchimento de uma quantidade razoável de critérios, o que torna o processo mais oneroso para o produtor/fornecedor. A exigência é que o produto licitado preencha um ou dois critérios considerados os mais importantes e que representam os principais impactos ao meio ambiente ou à saúde humana, do ciclo de vida desse produto.

No Brasil, esse processo poderia ser adotado e os termos de referência das compras públicas poderiam mesclar critérios de sustentabilidade com exigência de auditoria e critérios de sustentabilidade sustentados por autodeclarações do produtor/fornecedor. Dessa forma, os principais impactos dos processos produtivos dos produtos/serviços licitados poderiam ser verificados por meio de auditoria. Importante destacar que tal auditoria necessariamente deve ser feita por organismo acreditado pelo Instituto Nacional de Metrologia, Qualidade e Tecnologia (Inmetro), que por meio da Coordenação Geral de Acreditação (CGCRE) é o órgão de acreditação oficial do País.

A ideia é trazer credibilidade para o processo de compra pública sustentável e garantir que organismos realmente aptos seriam os responsáveis pelas auditorias.

Levando-se em consideração que o processo de verificação da sustentabilidade dos produtos licitados (auditoria) é oneroso, pode-se discutir a criação de um mecanismo de financiamento ou de subsídio para as micro e pequenas empresas com o objetivo de promover e incentivar a busca pelo aperfeiçoamento ambiental de seus processos produtivos e propiciar concorrência mais justa com empresas de maior porte e de maior faturamento econômico. Alternativas poderiam ser discutidas pelo Serviço Brasileiro de Apoio às micro e pequenas empresas (SEBRAE) que já possui linhas de financiamento para esse tipo de 
empresas e pelo Banco Nacional de Desenvolvimento (BNDES) para a viabilização de crédito análogo.

Entende-se que a elaboração de critérios ambientais com sistemas de verificação da sustentabilidade por organismos de terceira parte e a criação de mecanismos de financiamento para micro e pequenas empresas para viabilizar a participação ampla do setor empresarial pode se constituir em um conjunto de ações indutoras efetivas do aperfeiçoamento do processo de compras públicas sustentáveis no Brasil.

Além disso, com essas iniciativas, o Governo Brasileiro pode fortalecer seu papel de liderança como consumidor sustentável e contribuir de forma significativa para a mudança dos padrões de produção e de consumo vigentes para padrões considerados mais responsáveis.

\section{REFERÊNCIAS}

BIDERMAN, Rachel et al. Guia de compras públicas sustentáveis: uso do poder de compra do governo para a promoção de desenvolvimento sustentável. 2.ed. Rio de Janeiro: FGV, 2008.

BRASIL. Ministério do Meio Ambiente (MMA). Rotulagem ambiental: documento base para o Programa Brasileiro de Rotulagem Ambiental. Brasília: MMA/SPDS, 20p. 2002.

CORTEZ, Ana T.C; ORTIOGOZA, Silvia A.G. (org.). Consumo sustentável: conflitos entre necessidade e desperdício. São Paulo: Unesp, 2007.

COSTA, Carlos E. L. As licitações sustentáveis na ótica do controle externo. Monografia (especialista em auditoria e controle governamental) - Instituto Serzedello Corrêa, Brasília, 2011.

GROTE, U. Eco-labelling in agriculture, high-level pan-european conference on agriculture and biodiversity: towards integrating biological and landscape diversity for sustainable agriculture in europe. Strasbourg, March 4, 2002.

IPEA. Instituto de Pesquisa Econômica Aplicada. O Uso do poder de compra para a melhoria do meio ambiente. Série Eixos do Desenvolvimento Brasileiro. 
Comunicados do IPEA. n. 82. Sustentabilidade Ambiental no Brasil: biodiversidade, economia e bem-estar humano. 2011.

MPOG. Ministério do Planejamento, Orçamento e Gestão. Instrução Normativa $\mathrm{n}^{\circ}$ 01, de 19 de janeiro de 2010. Dispõe sobre os critérios de sustentabilidade ambiental na aquisição de bens, contratação de serviços e ou obras pela Administração Pública Federal direta, autárquica e fundacional e dá outras providências. DOU Seção I, n.13, de 20 de janeiro de 2010.

PNUMA. Programa das Nações Unidas para o Meio Ambiente. Considerações e recomendações

para as compras públicas sustentáveis no Brasil - Projeto Sustainable Public Procurement and Ecolabelling (SPPEL). Consultor: José Augusto A.K. Pinto de Abreu. Rio de Janeiro (2016).

PNUMA. Programa das Nações Unidas para o Meio Ambiente. Rumo ao consumo sustentável na América Latina e Caribe. Publicação de base para o Workshop sobre Consumo Sustentável na América Latina e Caribe. São Paulo: Nações Unidas, 2001. Disponível em: www.pnuma.org/eficienciarecursos/documentos/ conslacp.pdf.

PORTILHO, Fátima; RUSSO, Fátima F. Processo Marrakech - o consumo sustentável visto pelos organismos internacionais. In: ENCONTRO NACIONAL DA ANPPAS, IV, 2008, Brasília. Anais eletrônicos.

SETAC - Society of Environmental Toxicology and Chemistry. SETAC annual meeting, 23. North America: Achieving Global Environmental Quality. Integrating Science \& Management. Abstract Book, Utah, nov. 2002.

STERN, Nicholas. The economics of climate change. The Stern review. Cambridge University Press 2007.

VEIGA, José E. Desenvolvimento sustentável: o desafio do século XXI. Rio de Janeiro: Gramond, 2005. 
STAHEL, W. R. The circular economy. Nature. V. 531, p. 435-428, 2016.

YUAN, Z., BI, J., MORIGUICHI, Y. (2006). The circular economy: a new development strategy in China. Journal of Industrial Ecology, 10, 4-8.

\section{BIOGRAFIA DO AUTOR}

Antônio José Juliani é Engenheiro de Produção Química graduado na Universidade Federal de São Carlos (UFSCAR) e servidor público federal, lotado no Ministério da Economia (ME). Doutor em Desenvolvimento Sustentável pela Universidade de Brasília (CDS/UnB), trabalha com temas que relacionam as questões ambientais com a competitividade industrial. Dedica-se à promoção do uso da rotulagem ambiental tipo I como ferramenta de mercado para fortalecer a produtividade e a competitividade de produtos e de serviços nacionais em mercados globais. Atualmente, participa das discussões sobre a viabilidade da criação de um rótulo ambiental (selo Brasil), no âmbito do Governo Brasileiro.

E-mail: antonio.juliani@mdic.gov.br 